\title{
Critérios para a avaliação de materiais didáticos impressos de História da Ciência para a Educação a Distância ${ }^{+*}$
}

\author{
Edmundo Rodrigues Junior \\ Fernando J. Luna \\ Marília Paixão Linhares \\ Universidade Estadual Norte Fluminense \\ Campos dos Goytacazes - RJ
}

\section{Resumo}

Este artigo propõe critérios para a avaliação de materiais didáticos impressos (MDI) sobre história da ciência para a educação a distância (EAD). A construção dos critérios foi baseada nos documentos oficiais do ensino superior e médio do Brasil, em modelos de aprendizagens de professores descritos por Porlán and Rivero (1998), em livros da EAD e nos referenciais teóricos da história das ciências no ensino. Os critérios foram divididos em cinco blocos: Bloco I: legislação; Bloco II: elementos textuais; Bloco III: aluno da licenciatura; Bloco IV: referências, glossários e respostas e; Bloco V: projeto editorial. Dados do Censo, organizados pela Associação Brasileira de Educação a Distância (ABED, 2011) revelam que apesar do crescente desenvolvimento tecnológico, o material didático impresso ainda é o principal objeto de aprendizagem utilizado pelas instituições de ensino a distância. Os dados desse censo mostram uma evolução do número de matrículas dos alunos na Educação a Distância (EAD) entre os anos de 2009 e 2011. A construção dos critérios para a avaliação de MDI é rele-

\footnotetext{
${ }^{+}$Criteria to evaluate printed materials of History of Science for Distance Education

* Recebido: outubro de 2013.

Aceito: março de 2014.
} 
vante porque esse incremento de matrículas na EAD sinaliza para uma demanda maior de produção de objetos de aprendizagem gerando uma preocupação com a qualidade dos conteúdos e das atividades presentes nesses materiais. Talvez, os critérios para a avaliação de MDI de história da ciência, descritos nesse artigo, sejam o embrião para a construção de critérios para avaliar MDI de outras disciplinas da EAD. O conjunto desses instrumentos de avaliação poderia ser inserido em um desejável Programa Nacional do Livro Didático para os cursos superiores a distância, com o objetivo de melhorar a qualidade desses materiais.

Palavras-chave: Educação a distância. História da Ciência. Material Didático Impresso.

\begin{abstract}
This paper proposes criteria for the evaluation of printed materials (MDI) of History of Science for Undergraduate Distance Learning School. The construction of the criteria was based on official documents of Undergraduate and High School of Brazil, models of teacher training by Porlán and Rivero (1998) and in the theoretical History of Science teaching. The criteria were divided into five blocks: Block I: legislation, Block II: textual elements, Block III: Undergraduate student, Block IV: references, glossaries and answers and Block V: editorial design. Census Data, organized by the Brazilian Association for Distance Education $(A B E D, 2011)$ show that despite the increasing technological development, printed material is still the main learning object used by institutions for distance learning. The data from this census show a progress in the number of student enrollment in Distance Education between the years 2009 and 2011. The construction of the criteria for evaluation is relevant because this increase in enrollment in Distance Education signals a greater demand for the production of learning objects generating a concern on the quality of the content and exercises contained in these materials. Perhaps, the criteria to evaluate MDI of History of Science, that this article describes, are the beginning for the construction of criteria to evaluate MDI from other disciplines of EAD. This set of
\end{abstract}


assessment instruments could be inserted into a desirable National Textbook Program for Undergraduate Distance Learning Courses, aiming to improve the quality of these materials.

Keywords: Distance Education. History of Science. Printed materials.

\section{Introdução e objetivos}

Este trabalho estabelece critérios para a avaliação de livros didáticos ${ }^{1}$ de história da ciência para a educação a distância (EAD). Trata-se de uma proposta inovadora e tem como objetivo contribuir para a melhoria da qualidade desses materiais.

A preocupação com a qualidade dos livros didáticos não é assunto recente. Nosella (1981) analisou mais de vinte mil páginas de livros didáticos de diversas áreas e encontrou problemas como a desatualização das informações, veiculação de ideologias e preconceitos, deficiências metodológicas e explicações científicas equivocadas para as causas reais dos fenômenos naturais. Segundo Bizzo (1997) o livro didático era concebido tendo como prioridades as necessidades do professor, sem considerar o conhecimento e as necessidades dos alunos desestimulando-os a fazer leituras e interpretação. Ainda segundo esse autor, as sugestões das atividades experimentais muitas vezes colocavam os alunos e professores em situação de perigo (BIZZO, 1997).

Na década de 1990, o Ministério da Educação participou efetivamente da discussão sobre a qualidade dos livros escolares. O ano de 1993, em especial, representou um marco em relação à política voltada para materiais didáticos com a criação do Plano Decenal de educação para todos. Em sua dissertação de mestrado, Mantovani comenta que a prioridade do Plano Decenal estava relacionada à necessidade de melhoria qualitativa dos livros didáticos, capacitação adequada do professor para avaliar e selecionar os livros e a implementação de uma nova política para o livro didático no Brasil (MANTOVANI, 2009, p.35).

Para alcançar essa melhoria da qualidade do livro didático, realizou-se, em 1994, uma avaliação da qualidade dos conteúdos programáticos e dos aspectos pedagógicos e metodológicos dos dez títulos de cada área mais solicitados pelos professores às editoras em 1991, correspondentes às quatro séries iniciais do Ensi-

\footnotetext{
1 O livro didático na EAD também é denominado de Material Didático Impresso (MDI).
} 
no Fundamental (MANTOVANI, 2009, p.35). Após a leitura desses livros e consultas decorrentes da literatura educacional, uma equipe de especialistas do Ministério da Educação definiram os primeiros critérios para a avaliação dos livros didáticos. Eles foram concebidos inicialmente para a análise de livros didáticos de português, matemática, estudos sociais e ciências da $1^{\mathrm{a}}$ a $4^{\mathrm{a}}$ série (hoje, $2^{\circ}$ a $5^{\mathrm{o}}$ ano do ensino fundamental) destinados ao ensino presencial. Esses critérios ou descritores, como eram chamados, foram publicados no livro "Definição de critérios para Avaliação dos Livros Didáticos”, uma obra organizada pelo Ministério da Educação e do Desporto e pela Fundação de Assistência ao Estudante. Em 1997, o Ministério da Educação adquiriu livros didáticos de alfabetização, língua portuguesa, matemática, ciências, estudos sociais, história e geografia para todos os estudantes de $1^{\mathrm{a}}$ a $8^{\mathrm{a}}$ série (atualmente $2^{\circ}$ ao $9^{\circ}$ ano) do ensino fundamental público. Em 15 de outubro de 2003, a resolução $n^{\circ} .38$ do Conselho Deliberativo do Fundo Nacional de Desenvolvimento da Educação (CD/FNDE n ${ }^{\circ}$. 38) institui o Programa Nacional do Livro Didático para o Ensino Médio (PNLD). Em 24 de abril de 2007, a resolução CD/FNDE n ${ }^{\circ} 18$ regulamentou o Programa Nacional do Livro Didático para a Alfabetização de Jovens e Adultos (PNLA). Em 2008, foi publicado o primeiro guia de livros didáticos para a EJA ${ }^{2}$ (língua portuguesa e matemática) e, em 2011, foi publicado o segundo guia de livros didáticos para o EJA, contendo além de português e matemática, as disciplinas de história, geografia, artes ciências, inglês, alfabetização matemática, letramento e alfabetização linguística e uma disciplina de caráter interdisciplinar. Em 2009 e 2012, foram publicados o primeiro e o segundo guias dos livros didáticos para o ensino médio, contendo critérios para avaliar livros didáticos de física para o ensino médio.

Os critérios de avaliação descritos nos documentos supracitados estão direcionados para livros adotados na modalidade de ensino presencial e não devem ser tomados de maneira acrítica para a modalidade da educação a distância.

Sobre a educação a distância, Moran (2002) a define como “... o processo de ensino, mediado por tecnologias, onde professores e alunos estão separados espacial e/ou temporalmente." O correio, o rádio, a televisão, o vídeo e a internet, são exemplos dessas tecnologias, que promovem a educação a distância. Segundo Rodrigues (2011), as características atuais da EAD são: a separação espacial e temporal entre professor, aluno e instituição; a utilização sistemática de meios e recursos tecnológicos nos processos de comunicação; autoaprendizagem individual e/ ou coletiva; e as formas tutoriais para o esclarecimento de dúvidas dos alunos.

${ }^{2}$ EJA - Educação de Jovens e Adultos. 
A EAD no exterior e no Brasil não é assunto recente. Alguns compêndios citam as epístolas de São Paulo às comunidades cristãs da Ásia Menor, registradas na Bíblia, como a origem histórica da Educação a Distância (GOLVEIA; OLIVEIRA, 2006). No Brasil, os primeiros dados conhecidos da EAD são do início do século XX. Em 1904, O Jornal do Brasil registrou, na primeira edição da seção de classificados, um anúncio que oferece profissionalização por correspondência para datilógrafo. Em meados da primeira década do século XXI, o Ministério da Educação (MEC), através do artigo $2^{\circ}$ do decreto número 5622, de 2005, regulamentou a educação a distância no Brasil e estabelece os níveis em que essa modalidade pode ser ofertada, a saber: educação básica; educação de jovens e adultos; educação especial; educação profissional e educação superior.

O Censo de Educação a Distância do Brasil $\left(\mathrm{ABED}^{3}{ }^{3}, 2012\right)$ revelou que existiam 1424 cursos a distância em 2011 e que houve uma evolução do número de matrículas de alunos nessa modalidade de ensino; passando de 528.320 alunos em 2009 para 3.529.373 alunos em 2011. Este número pode ser ainda maior, se considerarmos que apenas 196 das 1424 instituições de ensino responderam aos questionários do censo enviados pelos pesquisadores da ABED.

Esse incremento de matrículas em EAD sinaliza para uma demanda maior de produção de objetos de aprendizagem, gerando uma preocupação com a qualidade dos conteúdos presentes nesses materiais. Segundo o Censo de Educação a distância (ABED, 2011), 46\% das instituições de ensino utilizam o material didático impresso, como principal objeto de aprendizagem em seus cursos. Talvez a predominância desse objeto de aprendizagem seja devido à grande acessibilidade entre os estudantes e o seu fácil deslocamento.

Dentro desse universo de expansão da EAD e de produção de objetos de aprendizagem, pretendemos propor critérios para a avaliação dos materiais didáticos impressos de história da ciência presentes nas licenciaturas em física a distância do Brasil.

A escolha da história da ciência como eixo norteador para a proposta de critérios ocorreu porque o ensino dessa disciplina procura apresentar o conhecimento científico como verdade relativa; porque procura considerar a influência de valores e interesses sobre a prática científica, buscando elencar os conteúdos de física aos seus aspectos sociais, históricos, culturais e econômicos. Essa característica interdisciplinar da história da ciência aparece implicitamente nas Diretrizes Curriculares Nacionais para a Formação de Professores da Educação Básica. Esse

${ }^{3}$ ABED-Associação Brasileira de Educação a Distância.

Caderno Brasileiro de Ensino de Física, v. 31, n. 2, p. 429-462, ago. 2014. 
documento sugere que o futuro professor do ensino básico deve reunir condições para superar a fragmentação dos conteúdos (BRASIL, 2002, p. 28).

Nesse sentido, o Material didático impresso de história da ciência para a EAD deve oferecer condições para integrar as diversas disciplinas, articulando o conhecimento disciplinar aos conhecimentos sociais, políticos e econômicos que influenciaram na construção de determinada teoria científica com o objetivo de formar o aluno cidadão.

Devido à expansão da EAD e a Importância da história da ciência no ensino, é necessário estabelecer critérios para se avaliar os atuais MDI de história da ciência da EAD com o propósito de contribuir para a melhoria da qualidade desses materiais.

\section{Definição e discussão dos critérios}

A determinação dos critérios para análise dos Materiais didáticos impressos de história da ciência para a EAD fundamentou-se na observação dos aspectos epistemológicos e pedagógicos. Eles foram estabelecidos tendo como referencial alguns documentos oficiais do ensino superior e médio, os referenciais teóricos da história da ciência no ensino, livros da EAD, três Materiais didáticos impressos de história da Ciência destinados aos cursos de licenciatura em física a distância e os modelos de aprendizagens de professores de ciências.

Sobre os documentos oficiais foram consultados inicialmente o Programa Nacional Dos Livros Didáticos de Física para o Ensino Médio (PNLD - Física) e da Educação de Jovens e Adultos (PNLD - EJA). É importante salientar que não existe PNLD para a educação superior (presencial e a distância), devido ao caráter facultativo desse segmento de ensino. No caso do ensino presencial, os livros didáticos em geral são estrangeiros e traduzidos, como os livros de física escritos em conjunto pelos autores norte-americanos: Resnick, Halliday e Krane (2007).

A EAD pública das Licenciaturas, através dos programas Pró-Licenciatura (PROLICEN) e Universidade Aberta do Brasil (UAB), orientam as instituições de ensino superior (IES) para elaborarem textos impressos e materiais didáticos complementares on line (Universidade Federal de Santa Catarina é exemplar típico); ou a utilização por uma IES de textos produzidos em outra (Universidade Federal de Goiás usa alguns textos de física da Universidade Federal de Santa Catarina).

Sabendo-se que os cursos de formação de professores possui um compromisso direto com a educação básica e, devido à ausência do PNLD para as licenciaturas públicas, construímos nossa proposta de critérios a partir das matrizes clássicas do PNLD/ Ensino Médio/Física e PNLD/EJA. Essas matrizes possuem 
orientações para a avaliação de livros didáticos de Física para a educação básica. Algumas dessas orientações sugerem que os conteúdos de física desses livros devem estar relacionados com o seu desenvolvimento histórico:

Apresenta os conteúdos da Física considerando a sua contextualização, seja em relação a aspectos sociais históricos, culturais e econômicos, seja em relação àqueles do cotidiano em que suas utilizações se façam pertinentes, evitando a utilização de contextualizações artificiais para esses conteúdos (PNLD/FÍSICA, 2012, p. 21).

Evidencia a historicidade do conhecimento científico (PNLD/EJA, 2011, p.233).

Além dos PNLD, consultou-se para a realização desse trabalho a Lei de Diretrizes e Bases (LDB), a Legislação em EAD, o parecer e a resolução do $\mathrm{CNE} \mathrm{CP}^{4}$ que Institui Diretrizes Curriculares Nacionais para a Formação de Professores da Educação Básica, os Parâmetros Curriculares Nacionais para o Ensino Médio - Ciência da Natureza (PCNEM e $\left.\mathrm{PCN}^{+}\right)$.

Os critérios encontram respaldo na LDB, através do artigo 36, parágrafo $2^{\circ}$ e; do artigo 43 , parágrafo $1^{\circ}$. Em relação à legislação EAD os critérios foram estabelecidos através do artigo $4^{\circ}$, inciso II, parágrafo $1^{\circ}$ do decreto $\mathrm{n}^{\circ} 5622$ de 2005.

Os pareceres do Conselho Nacional de Educação/ Conselho Pleno (CNE/CP/2001 e CNE/CP/2005) e as resoluções de números 02 e 09 do Conselho Nacional de Educação $\left(n^{\circ} .02\right.$ e 09/CNE 2002) são documentos de análise de Ferreira e Meirelles (2011) em seu artigo, apresentado ao VIII Encontro Nacional de Pesquisa em Ensino de Ciências (ENPEC). As autoras identificam nesses documentos algumas características que remetem indiretamente ao ensino de ciências. Essas características estão relacionadas à importância do ensino de ciências para a formação geral do cidadão, o conteúdo curricular de ciências, a importância da pesquisa para a compreensão da ciência, a interação das especificidades entre os professores, a prática no ensino de ciências, a organização curricular e a carga horária dedicada ao ensino de ciências.

A abordagem da história da ciência nesse contexto aparece indiretamente relacionada às propostas interdisciplinares, conforme palavras de Ferreira e Meirelles (2011):

${ }^{4} \mathrm{CNE} / \mathrm{CP}$ - Conselho Nacional de Educação/ Conselho Pleno. 
Para exercer a interdisciplinaridade exigida no documento (CNE/CP 2005) é necessário ter uma vivência considerável em ciências. Ser cientificamente culto envolve simultaneamente aprender ciências (conceitos), aprender sobre ciências (métodos, evolução, história da ciência, atitude de abertura e interesse por relações complexas entre ciências, tecnologia, sociedade e ambiente) e aprender a fazer ciência (pesquisa e resolução de problemas). (HODSON apud FERREIRA; MEIRELLES, 2011).

Os $\mathrm{PCN}^{+}$também sugere abordar aspectos históricos no ensino:

Tanto no aprendizado de história quanto no de ciências é possível compreender como, em determinados períodos e circunstâncias, o conhecimento técnico-científico se mostrou mais determinante para o domínio militar, discutindo até mesmo aspectos éticos dos meios de distribuição de massa, e como, em outros períodos, foi mais essencial para a hegemonia econômica, ou como, em geral, ambos esses domínios frequentemente se sobrepõem. As máquinas térmicas na revolução industrial inglesa, a tecnologia nuclear, na segunda guerra mundial e na "guerra fria", os semicondutores e a informática, na terceira revolução industrial, são só alguns exemplos. Esse exercício histórico daria aos estudantes uma oportunidade de questionar e compreender melhor processos sociais, econômicos e culturais passados e contemporâneos e, além disso, auxiliaria a construir uma visão das Ciências da Natureza associada a outras dimensões da vida humana (PCN+, p.18).

Vê-se a importância atribuída à história da ciência como eixo norteador para relacionar os conhecimentos científicos aos conhecimentos sociais, econômicos e culturais. Esses debates externos também são preocupações de Hessen e Merton (apud BORGES, 1996) (influência sócio-política e econômica) e Feyerabend e Morin, (apud BORGES, 1996) (sociológica e cultural).

Para promover a articulação necessária, os conteúdos do Material Didático Impresso (MDI) de história da ciência para a EAD devem ser integrados ao seu contexto de produção, seja ele político, social ou econômico. Essa orientação favorece a prática interdisciplinar e corrobora com Shulman (1986). Este autor destaca que o conhecimento da disciplina a ser ensinada deve estabelecer relações com outras áreas do conhecimento. No âmbito da formação inicial docente, Porlán e Rivero (1998, p. 105) afirma que os professores sofrem de carência de História da Ciência (HC) e Filosofia e Sociologia da Ciência (FSC) e, por isso, tem dificuldades de promover a integração dos conhecimentos recebidos nas disciplinas universitárias. 
A história da ciência também está presente no PNLD de Física para o Ensino Médio. Esse documento orienta a articulação entre os conhecimentos científicos e os aspectos históricos, tecnológicos, sociais e econômicos, com o objetivo de formar o aluno cidadão (PNLD-FÍSICA, 2012, p. 8).

O PNLD- EJA sugere no critério 4 que a obra destinada a jovens e adultos deve evidenciar a historicidade do conhecimento científico (PNLD-EJA, 2011, p. 233). É fundamental considerar os critérios de avaliação do MDI descrito nesse documento, porque segundo o Censo do INEP ${ }^{5}$, os alunos dos cursos a distância possuem, em média, 33 anos e constituem um público com idade mais elevada do que a do ensino presencial (CENSO EAD BR, 2012).

O ensino de história da ciência, segundo Matthews (1995), promove uma compreensão melhor dos conceitos científicos porque: mostra o desenvolvimento e aperfeiçoamento da ciência, demonstra que a ciência é mutável e instável e motiva os alunos para aprender. Na obra, A Natureza e os Gregos, Erwing Schrödinger expressou seu interesse pela história da ciência, ao revelar que ao mergulhar no pensamento original de um filósofo ou cientista, reunimos elementos para uma visão mais crítica da ciência atual (SCHRÖDINGER, 2003).

Sobre os textos da EAD, Preti (2010) sugere que linguagem escrita presente no livro em EAD deve ser dialógica, com o objetivo de mediar a comunicação ente alunos com o professor. Além disso, ele sugere o uso de iconografias (pequenas ilustrações que destacam tópicos, conceitos ou exercícios importantes), glossários e referências comentadas, localizadas ao final do livro para o aluno ter uma ideia inicial da obra a ser consultada, persuadindo-o a buscá-la.

A seguir, descreve-se a trajetória da pesquisa para a aquisição dos materiais didáticos impressos que servem de referência para a elaboração dos critérios:

Pesquisou-se no site (e MEC) os cursos de licenciatura em física a distância do Brasil cadastrados pelo MEC. Encontrou-se apenas seis cursos de licenciatura em física a distância com natureza jurídica privada; três cursos de licenciatura em física a distância com natureza jurídica pública estadual e 15 cursos de licenciatura em física a distância com natureza jurídica pública federal, distribuídos em várias unidades federativas brasileiras.

O curso de licenciatura em Física a distância da Universidade Federal de Santa Catarina (UFSC), ocupa a maior parte do território nacional, estando presente em quinze estados brasileiros. Em segundo lugar aparece a Universidade Federal

${ }^{5}$ INEP- Instituto Nacional de Estudos e Pesquisas Educacionais Anísio Teixeira.

Caderno Brasileiro de Ensino de Física, v. 31, n. 2, p. 429-462, ago. 2014. 
do Rio Grande do Norte (UFRN), presente em quatro unidades federativas do Brasil.

Em seguida, entramos em contato por e-mail com essas instituições solicitando os materiais didáticos impressos de história da ciência utilizados em seus cursos. Foram adquiridos e consultados os materiais das Universidades Federais do Rio de Janeiro, (DIAS; SAPUNARU, 2013), de Santa Catarina, (PEDUZZI, 2011) e do Espírito Santo, (TORÍBIO, 2012). A organização e os conteúdos presentes nesses materiais também ajudaram na elaboração dos critérios.

Para esse trabalho, foi consultado apenas as amostras das universidades federais, uma vez que os cursos de licenciatura em física a distância dessas instituições estão presentes na maioria dos estados brasileiros; e, também porque as instituições privadas disseram, por telefone, que não disponibilizariam os materiais didáticos impressos deles para consulta.

Além dos materiais didáticos de história da ciência para a educação a distância, consultamos os modelos de aprendizagem de professores de ciências, descritos por Porlán e Rivero (1998, p. 125). Tínhamos o objetivo de entender como os alunos da licenciatura aprendem. Tais modelos são descritos como: recepção, assimilação, descoberta, substituição de conhecimentos e evolução de conhecimento.

O foco da aprendizagem receptiva consiste na memorização do conteúdo e não considera o conhecimento prévio do aluno. A aprendizagem por assimilação vincula os conhecimentos novos aos conhecimentos escolares anteriores. A aprendizagem por substituição de conceitos ocorre quando o aluno consegue substituir o seu conhecimento prévio pelo conhecimento científico. Por fim, a aprendizagem por evolução de conhecimento ocorre por mudanças conceituais, no sentido de evolução de conceitos já existentes. Algumas características desses modelos serão utilizadas como proposta de critérios, descritos no Bloco 3.

Tendo a história da ciência, os modelos de aprendizagem dos professores de ciências e as sugestões de escrita de MDI para a EAD como eixos norteadores, organizamos os critérios de avaliação em blocos: Bloco 1: Legislação; Bloco 2: Elementos textuais; Bloco 3: Alunos da licenciatura; Bloco 4: Referências, Glossários e Respostas e Bloco 5: Projeto Editorial.

O Bloco 1 traz a Legislação, as diretrizes e as normas oficiais, relativas ao ensino superior e médio (constituição brasileira; LDB 1996; Diretrizes para a formação de professores da Educação Básica; Resoluções e pareceres do CNE e da Secretaria de educação a distância, $\mathrm{PCN}, \mathrm{PCN}^{+}$, PNLD.

Esse bloco traz indicadores para que o material didático impresso história da ciência para a EAD favoreça o entendimento dos aspectos sociais e econômicos 
que contribuíram para o desenvolvimento de determinada teoria científica. A revelação desses aspectos auxilia na formação de um aluno crítico e reflexivo, contribuindo, por exemplo, para análise das propostas dos políticos, principalmente aquelas relacionadas aos temas da Ciência, Tecnologia e Sociedade e do Ambiente tais como as construções de usinas hidrelétricas, a utilização da energia nuclear e o uso de inseticidas na agricultura. Assim, os conteúdos de história da ciência precisam ser refletidos, contextualizados e aproximados da curiosidade e vivência dos estudantes.

O Bloco 2 apresenta critérios relacionados ao texto de apresentação autor, aos conteúdos teóricos dos capítulos, às sugestões de exercícios avaliativos e , atividades práticas incluindo experimentos históricos e o uso do teatro para explicar a história da ciência. Apresenta também, critérios relacionados ao uso de estudos de caso históricos no ensino. Para Tardiff (2002), o conhecimento do professor é diferente do conhecimento do especialista na disciplina e tem o foco no saber a disciplina para ensiná-la. Assim, o material didático impresso deve apresentar sugestões metodológicas para ensinar os conteúdos da história da ciência.

O texto de apresentação "é a porta de entrada da disciplina, é o convite para participar de caminhada rumo à aprendizagem e ao sucesso" (PRETI, 2010, p. 91). Assim, ele deve criar um clima de relação pessoal com o estudante, apresentando o autor de maneira informal. Para isso é necessário que ele seja escrito na segunda pessoa do singular ou na primeira pessoa do plural evidenciando uma proximidade entre o autor e o leitor. O texto de apresentação deve também: expor os objetivos da história da ciência, para que o estudante consiga atribuir significado aquilo que está lendo; abordar os conhecimentos necessários para a aprendizagem da história da ciência, para que o estudante possa identificar possíveis lacunas antes de começar o estudo da história da ciência; apresentar a importância da história da ciência no contexto das demais disciplinas do curso, no campo da ciência e da humanidade; apresentar os capítulos e justificar os seus conteúdos; sugerir perguntas que podem aparecer no início da disciplina ou que estarão no centro do estudo ao longo da disciplina história da ciência. Por fim, o texto de apresentação deve valorizar as concepções prévias dos estudantes adquiridas em outro momento da sua vida cotidiana.

Os conteúdos teóricos de história da ciência podem erigir aspectos relacionados à visão internalista e externalista da história da ciência. As intervenções pedagógicas simultâneas desses aspectos revelam tanto os aspectos referentes à evolução dos conhecimentos científicos como também os aspectos externos que transcendem a construção do conhecimento científico, contribuído assim para que o aluno adquira uma visão ampla da construção do conhecimento científico. Essas 
leituras convergem para uma discussão interdisciplinar entre a física e química (CORDEIRO; PEDUZZI, 2010) e entre a física, arte e matemática (GUERRA et al., 2010).

O uso de experimentos históricos na sala de aula é abordado nos trabalhos de PORTO et al., 2010; RINALDI; GUERRA, 2011; MEDINA; GUERRA, 2010. Esses autores apresentam propostas para trabalhar experimentos históricos no ensino médio presencial. A intervenção pedagógica ocorreu através de teatro (MEDINA; GUERRA, 2010) e através da análise questionários diagnósticos (PORTO et al., 2010 e (RINALDI; GUERRA, 2011)), revelando assim a importância dos experimentos históricos para a aprendizagem de conceitos científicos, quanto para apresentar uma visão mais ampla da construção da ciência.

$\mathrm{O}$ estudo de caso histórico se caracteriza por princípios gerais que possibilitem o resgate do contexto em que se deu algum problema marcante na ciência (STINNER, 2003). Ainda segundo esse autor, as diretrizes para a elaboração de um estudo de caso são:

a) Escolher um evento marcante no desenvolvimento da ciência e identificar a ideia central.

b) Mapear o contexto em torno da ideia unificadora central.

c) Criar uma história, que pode ser linear ou não, que dramatize e clareie o significado da ideia. É importante identificar um fato associado com uma pessoa, ou pessoas, encontrar opositores ou eventos conflitantes e marcantes;

d) Fornecer ao estudante elementos que possam ser relacionadas com seu dia-a-dia, buscando dentro do caso estudado, vínculos com o cotidiano do aluno;

e) Assegurar que a ideia principal, concepções e problemas de um tópico sejam gerados do contexto de forma natural;

f) Assegurar uma linha que garanta a precisão e a generalização;

g) Resolver os conflitos que foram gerados pelo contexto e encontrar conexões entre ideias e concepções discutidas e ideias atuais.

O uso de estudo de caso no contexto educacional, proveniente de algum episódio histórico favorece, de acordo com El Hani (2006), a aprendizagem dos conceitos físicos e permite a reflexão dos aspectos da natureza da ciência, pois possibilita um estudo detalhado dos fatos históricos, sociais e culturais envolvidos no trabalho científico.

Segundo Reis e Linhares (2011), a metodologia do estudo de caso envolve três fases:

a) $1^{a}$ fase: leitura do texto e imediata postagem no ambiente virtual de aprendizagem de uma resposta que indicará a concepção do aprendiz em relação a 
uma questão.

b) $2^{a}$ fase: tempo para ler, resenhar e discutir materiais disponibilizados no ambiente.

c) $3^{a}$ fase: elaboração de solução que deve ser defendida pelo aprendiz perante o professor e os colegas no ambiente virtual de aprendizagem e/ou presencialmente.

O estudo de caso é uma síntese do episódio histórico, adaptado para a utilização no ensino segundo as diretrizes apresentadas por Stinner (2003).

O Bloco 3 contém indicadores para avaliar se o material didático impresso de história da ciência para a EAD. Esse bloco reúne subsídios para promover a evolução do conhecimento do aluno de licenciatura em relação aos conteúdos de história da ciência e sua práxis docente. Essas foram carências detectadas nos materiais didáticos impressos consultados de Dias e Sapunaru (2013), Peduzzi (2011) e Toríbio (2012), que descrevem muito bem a evolução das ideias da física, mas não oferecem maneiras adequadas para verificar o aprendizado do aluno, tanto em relação aos conteúdos de história da ciência, quanto em relação à transposição didática de tais conteúdos. Acreditamos que o aluno aprenderá de forma adequada se o material didático impresso contemplar os modelos de aprendizagens descritos por Porlán e Rivero (1998, p. 125) como: assimilação, descoberta e evolução de conhecimento. Entendo também que o MDI possa ser um veículo para a articulação entre a história da ciência e as estratégias de ensino dessa disciplina. Assim, o MDI deve oferecer condições para:

a) Promover a aprendizagem significativa, entendendo significativo, o conhecimento que pode ser conectado com aprendizagens escolares anteriores (aprendizagem por assimilação).

b) Incentivar a interação ativa dos alunos da licenciatura com o próprio material didático impresso e com o ambiente virtual de aprendizagem (Aprendizagem por descoberta).

c) Possibilitar o aluno da licenciatura a substituir as concepções espontâneas pelos conhecimentos científicos, permitindo que a aprendizagem aconteça por mudanças conceituais, no sentido de evolução de conceitos já existentes (aprendizagem por evolução de conhecimento).

d) Permitir ao aluno da licenciatura refletir sistematicamente sobre sua prática docente, para modificar seu desempenho e para se adaptar às propostas inovadoras.

e) Fomentar a construção coletiva do conhecimento, levando o aluno da licenciatura a interagir com seu colega ou tutor. 
f) Oferecer ao aluno da licenciatura subsídios teóricos - metodológicos para a aprendizagem conceitual de alguns tópicos da disciplina física e, sua aplicação em sala de aula.

g) Oferecer ao aluno da licenciatura subsídios teóricos - metodológicos para a aprendizagem conceitual de alguns tópicos da disciplina física e, sua aplicação em sala de aula.

O Bloco 4 apresenta critérios relacionados aos elementos pós-textuais como referências, glossários e respostas das questões propostas no MDI.

Sobre as referências, Preti (2010) comenta que:

[...] mais do que uma lista extensa de obras, que o estudante dificilmente irá ler ou terá dificuldade para encontrar no município onde reside ou na biblioteca do Polo, é aconselhável indicar de três a cinco obras que, em seu entender, o estudante deverá ler e, se possivel, adquirir (PRETI, 2010, p. 104).

Assim, as referências principais utilizadas no MDI para a EAD são fundamentais para o aluno ter uma ideia inicial da obra a ser consultada, e serve para incentiva-lo a buscá-la.

Sobre o glossário, Preti (2010) comenta:

[...] necessário quando no texto há muitos termos novos para o estudante, $e$ ele teria dificuldades para compreendê-los ao consultar, por exemplo, um dicionário. Uma sugestão: caso sejam poucos e breve sua explicação, você pode colocá-los no interior do texto (em caixa-texto, na lateral da página); caso sejam muitos ou extensos, é melhor colocá-los ao final do MDI para não quebrar o ritmo de leitura elou "poluir" visualmente o texto (PRETI, 2010, p. 106).

Assim, o glossário é necessário para a compreensão rápida de algumas palavras que o aluno poderá não entender.

Sobre as respostas comentadas, Preti (2010), afirma que:

Não se trata de colocar simplesmente o "gabarito" ou dar a resposta "correta". É mais pedagógico oferecer ao estudante elementos chave, pistas sobre o conteúdo de possíveis respostas corretas, propor explicações relativas ao processo, esclarecer os passos que conduzem à resolução, justificar a resposta correta, apontar possiveis erros (respostas "erradas") que o estudante pode ter cometido (comuns e previsiveis, a partir de sua experiência docente). Somem-se a isso palavras de elogio ao estudante (por seus acertos), de estímulo (diante de erros) e de orientação (PRETI, 2010, p. 107). 
É importante salientar que a mera existência de atividades sugeridas num MDI, não seria um bom indicador da qualidade do material. As respostas dos exercícios propostos no material didático impresso deve orientar o estudante sobre os caminhos que levam à resolução das questões e justificando a resposta correta (se existir), mostrando possíveis respostas equivocadas que o estudante possa ter feito. O processo de ensino aprendizagem atual da EAD disponibiliza apoio pedagógico aos discentes, permitindo que eles esclareçam suas dúvidas com tutores a distância através de um ambiente virtual de aprendizagem (AVA) ou, com tutores presenciais, através do polo de ensino presencial. Todavia, muitas vezes, os tutores demoram para responder aos questionamentos dos estudantes (devido à quantidade de alunos), produzindo um sentimento de "abandono pedagógico" dos discentes. Esse é mais um motivo pelo qual o material didático impresso em EAD deve conter glossários, referências e respostas comentadas. Além disso, o aluno EAD não possui a presença física do professor para sanar suas dúvidas de forma imediata, o que justifica a necessidade de um material mais autônomo.

O Bloco 5 apresenta critérios para uma adequação da estrutura editorial e do projeto gráfico aos objetivos didático-pedagógicos do MDI para a EAD. Esse bloco é formado de critérios para avaliar principalmente o sumário, as ilustrações e as iconografias do material didático impresso para a EAD.

Sobre os sumários, Preti (2010) sugere que ele indique, de maneira organizada e didática, a seleção e sequência do conteúdo abordado nos capítulos (PRETI, 2010, p. 89). Em relação às ilustrações, Behar (2009) sugere a utilização das ilustrações na educação a distância, requer um planejamento prévio levando em conta o conteúdo que está sendo utilizado e o público que está sendo abordado, para que o aluno seja capaz de refletir a partir delas (BEHAR, 2009, p. 39). Os ícones são pequenas ilustrações definidas no projeto gráfico que servem para sinalizar a intenção do autor sobre alguns destaques a serem dados no texto (PRETI, 2010, p. 114).

Assim as ilustrações, ícones ou tabelas devem ser de fácil compreensão, estarem integrados ao texto e devem ser empregadas em quantidade suficiente para o aprendizado do aluno.

\section{Ficha para avaliação de MDI de história da Ciência para a EAD}

A elaboração dos critérios foi fundamentada na leitura de alguns textos tais como documentos oficiais do ensino médio, modelos de formação de professores e livros didáticos de história da ciência para a EAD adotados nos cursos de licenciatura em física a distância das Universidades Federais do Espírito Santo 
(TORÍBIO, 2012), de Santa Catariana (PEDUZZI, 2011) e do Rio de Janeiro (DIAS; SAPUNARU, 2013); livros da educação a distância (BEHAR, 2009; PRETI, 2010) e alguns referenciais teóricos sobre a história da ciência no ensino, como por exemplo, (GUERRA, 2010; MATTHEWS, 1995; PEDUZZI, 2011). Com o objetivo de facilitar a avaliação do MDI de história da ciência para a EAD, esses critérios foram reunidos numa ficha de avaliação. O MDI só pode receber um conceito em cada item analisado. Nossa proposta de critérios considera prioritária a articulação de situações de ensino-aprendizagem que priorizassem a postura crítica, dialógica e reflexiva. Os critérios abaixo mencionados são um conjunto de sugestões que pode contribuir para uma futura avaliação de HC/FSC dos textos impressos de licenciatura em física MEC/EAD, mas também podem ser adaptados para o ambiente virtual de aprendizagem.

A seguir se encontra a ficha de avaliação com a proposta dos critérios.

\section{BLOCO 1 - LEGISLAÇÃO}

Respeito à Legislação, às diretrizes e às normas oficiais, relativas ao ensino superior (constituição brasileira; LDB 1996; Diretrizes Curriculares para a Formação de Professores do Ensino Básico, resoluções e pareceres do CNE, Legislação em EAD).

Quadro 1 - Ficha de avaliação para o Bloco Legislação e Cidadania.

\begin{tabular}{|c|c|c|c|}
\hline $\mathrm{N}^{\mathrm{o}}$ & Critério & Sim & Não \\
\hline 1.1 & $\begin{array}{l}\text { Estimula a criação cultural e o desenvolvimento do espírito } \\
\text { científico e do pensamento reflexivo (LDB, artigo } 43 \text {, pa- } \\
\text { rágrafo } 1^{\circ} \text { ). }\end{array}$ & & \\
\hline 1.2 & $\begin{array}{l}\text { Favorece a aprendizagem como processo de construção de } \\
\text { conhecimentos, habilidades e valores em interação com a } \\
\text { realidade e com os demais indivíduos, no qual são coloca- } \\
\text { das em uso capacidades pessoais (DCFPEB }{ }^{6} \text {, art. } 3^{\circ} \text {, inciso } \\
\text { II, alínea b). }\end{array}$ & & \\
\hline 1.3 & $\begin{array}{l}\text { Contribui para o aprendizado do aluno, permitindo que ele } \\
\text { construa significado do conteúdo de aprendizagem (Parecer } \\
\text { CP, 2001, p. 32). }\end{array}$ & & \\
\hline
\end{tabular}

${ }^{6}$ DCFPEB - Diretrizes Curriculares para a Formação de Professores da Educação Básica. 


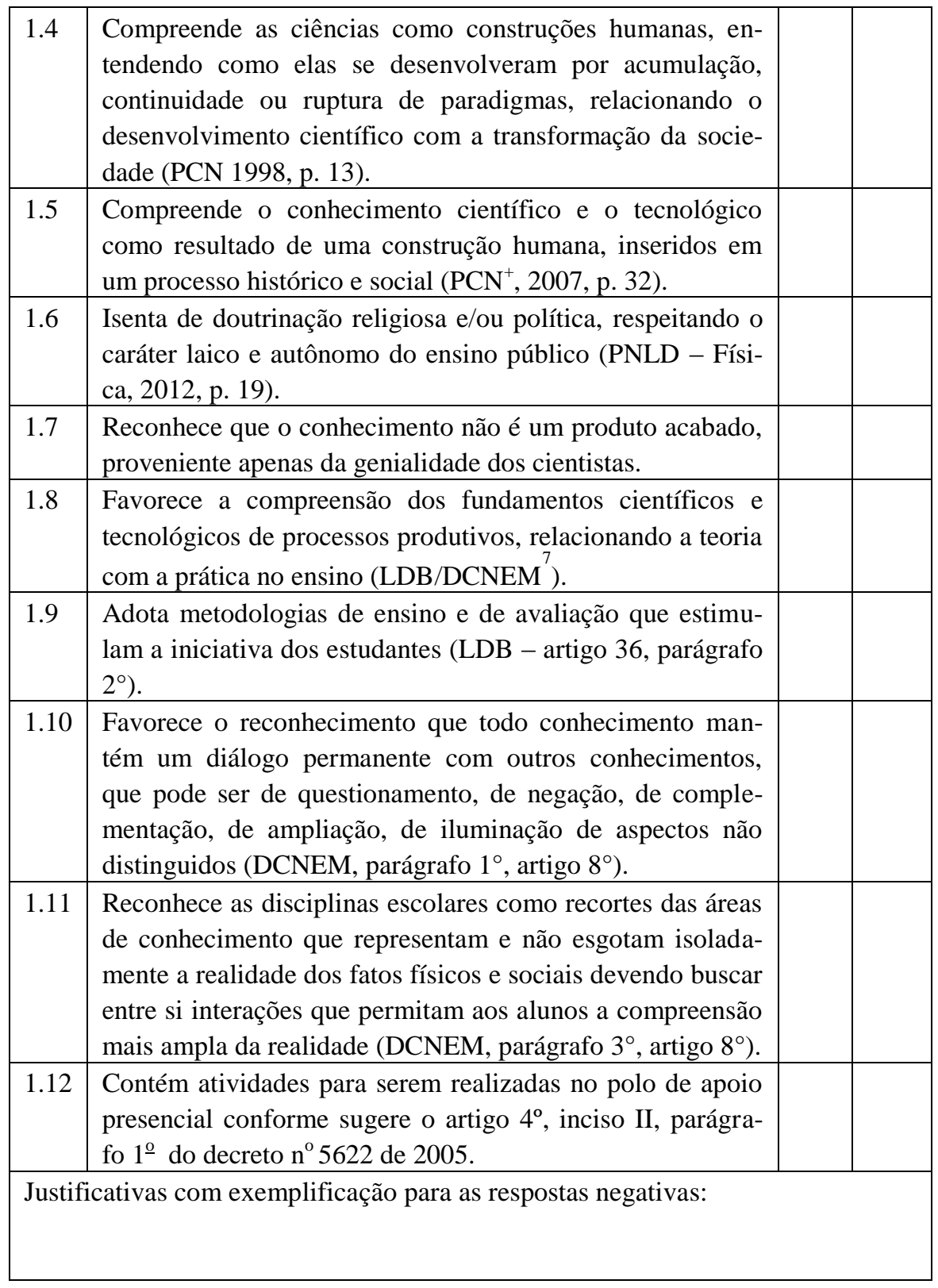

${ }^{7}$ DCNEM - Diretrizes Curriculares Nacionais para o Ensino Médio.

Caderno Brasileiro de Ensino de Física, v. 31, n. 2, p. 429-462, ago. 2014. 


\section{BLOCO 2 - ELEMENTOS TEXTUAIS}

São elementos que se encontram presentes no corpo do material didático impresso, ele é formado pelo texto de apresentação do autor, os conteúdos teóricos dos capítulos bem como as sugestões de exercícios e atividades práticas incluindo experimentos históricos e o uso do teatro para explicar a história da ciência.

Quadro 2 - Ficha de avaliação para o Bloco Elementos Textuais.

\begin{tabular}{|c|c|c|c|c|}
\hline $\mathrm{N}^{\mathrm{O}}$ & Critério & Sim & Parcial & Não \\
\hline 2.1 & $\begin{array}{l}\text { O texto de apresentação utiliza o pronome pessoal de } \\
\text { tratamento "você" e os verbos, consequentemente, } \\
\text { estão conjugados na } 3^{\text {a }} \text { pessoa do singular, evidenci- } \\
\text { ando uma linguagem de aproximação entre autor e } \\
\text { leitor. } \\
\text { e/ou } \\
\text { O texto de apresentação está escrito na } 1^{\text {a }} \text { pessoa do } \\
\text { plural e os verbos, consequentemente, estão conju- } \\
\text { gados na } 1^{\text {a }} \text { pessoa do plural, mostrando que o autor } \\
\text { é audiência dos seus próprios escritos e que também } \\
\text { está inserido no processo de ensino-aprendizagem. }\end{array}$ & & & \\
\hline 2.2 & $\begin{array}{l}\text { O texto de apresentação cria um clima de relação } \\
\text { pessoal com o estudante, apresentando o autor de } \\
\text { maneira informal. }\end{array}$ & & & \\
\hline 2.3 & $\begin{array}{l}\text { O texto de apresentação expõe os objetivos da histó- } \\
\text { ria da ciência, para que o estudante consiga atribuir } \\
\text { significado aquilo que está lendo. }\end{array}$ & & & \\
\hline 2.4 & $\begin{array}{l}\text { O texto de apresentação aborda os conhecimentos } \\
\text { necessários para a aprendizagem da história da ciên- } \\
\text { cia, para que o estudante possa identificar possíveis } \\
\text { lacunas antes de começar o estudo da história da } \\
\text { ciência. }\end{array}$ & & & \\
\hline 2.5 & $\begin{array}{l}\text { O texto de apresentação apresenta a visão da história } \\
\text { da ciência, sua importância no contexto das demais } \\
\text { disciplinas do curso, no campo da ciência e da hu- } \\
\text { manidade. }\end{array}$ & & & \\
\hline
\end{tabular}




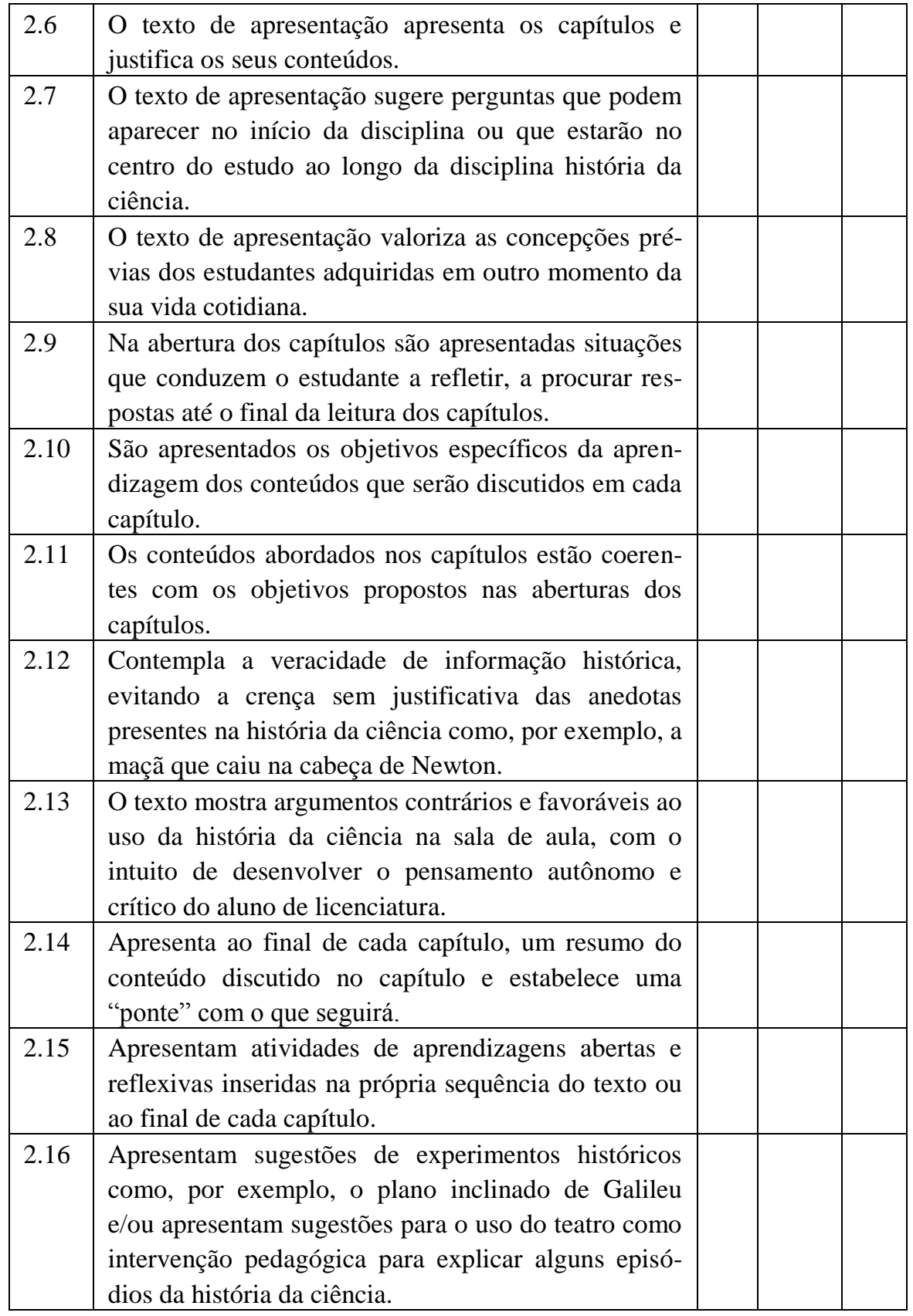

Caderno Brasileiro de Ensino de Física, v. 31, n. 2, p. 429-462, ago. 2014. 


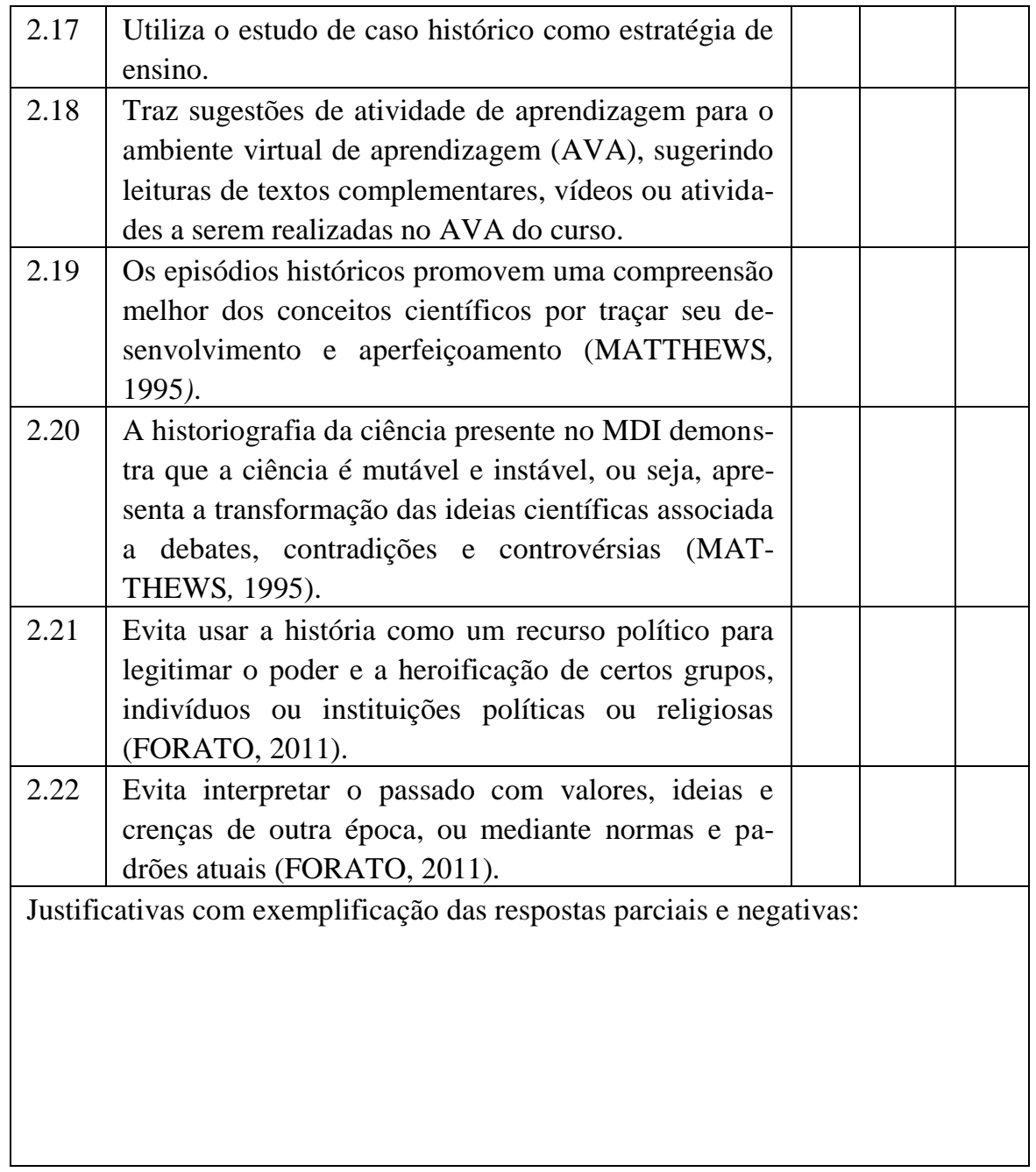

\section{BLOCO 3 - ALUNO DA LICENCIATURA}

Observância das características dos modelos de formação de professores de física que conduz a aprendizagem significativa de história da ciência e adoção de uma postura reflexiva em relação ao ensino. 
Quadro 3 - Ficha de avaliação para o Bloco referências, glossários e respostas.

\begin{tabular}{|c|c|c|c|}
\hline $\mathrm{N}^{\mathrm{O}}$ & Critério & Sim & Parcial Não \\
\hline 3.1 & $\begin{array}{l}\text { Valoriza a aprendizagem significativa, entendendo sig- } \\
\text { nificativo, aquilo que pode ser conectado com aprendi- } \\
\text { zagens escolares anteriores. }\end{array}$ & & \\
\hline 3.2 & $\begin{array}{l}\text { Incentiva a interação ativa dos alunos da licenciatura } \\
\text { com o próprio material didático impresso e com o ambi- } \\
\text { ente virtual de aprendizagem. }\end{array}$ & & \\
\hline 3.3 & $\begin{array}{l}\text { Possibilita o aluno da licenciatura a substituir as con- } \\
\text { cepções espontâneas pelos conhecimentos científicos, } \\
\text { permitindo que a aprendizagem aconteça por mudanças } \\
\text { conceituais, no sentido de evolução de conceitos já } \\
\text { existentes. }\end{array}$ & & \\
\hline 3.4 & $\begin{array}{l}\text { Permite ao aluno da licenciatura refletir sistematicamen- } \\
\text { te sobre sua prática docente, para modificar seu desem- } \\
\text { penho e para se adaptar às propostas inovadoras. }\end{array}$ & & \\
\hline 3.5 & $\begin{array}{l}\text { As atividades no material impresso fomenta a constru- } \\
\text { ção coletiva do conhecimento, levando o aluno da licen- } \\
\text { ciatura a interagir com seu colega ou tutor. }\end{array}$ & & \\
\hline 3.6 & $\begin{array}{l}\text { Oferece ao aluno da licenciatura subsídios teóricos - } \\
\text { metodológicos para a aprendizagem conceitual de al- } \\
\text { guns tópicos da disciplina física e, sua aplicação em sala } \\
\text { de aula. }\end{array}$ & & \\
\hline 3.7 & $\begin{array}{l}\text { Oferece ao aluno da licenciatura subsídios teóricos - } \\
\text { metodológicos para a aprendizagem e o ensino da natu- } \\
\text { reza da ciência a partir da história da ciência. }\end{array}$ & & \\
\hline \multicolumn{4}{|c|}{ Justificativas com exemplificação das respostas parciais e negativas: } \\
\hline
\end{tabular}




\section{BLOCO 4 - REFERÊNCIAS, GLOSSÁRIOS E RESPOSTAS.}

Observância das características das referências bibliográficas, dos glossários e a maneira de fornecer as respostas das atividades propostas no material didático impresso.

Quadro 4 - Ficha de avaliação para o Bloco referências, glossários e respostas.

\begin{tabular}{|c|c|c|c|c|}
\hline $\mathrm{N}^{\mathrm{O}}$ & Critério & Sim & Parcial & Não \\
\hline 4.1 & $\begin{array}{l}\text { As referências das obras citadas nos capítulos estão } \\
\text { escritas nas normas da ABNT. }\end{array}$ & & & \\
\hline 4.2 & $\begin{array}{l}\text { Apresenta uma breve descrição das referências prin- } \\
\text { cipais utilizadas no material didático impresso, para o } \\
\text { aluno ter uma ideia inicial da obra a ser consultada, } \\
\text { persuadindo-o a buscá-la. }\end{array}$ & & & \\
\hline 4.3 & $\begin{array}{l}\text { Apresenta glossário de vocábulos, necessário para a } \\
\text { compreensão rápida de algumas palavras que o aluno } \\
\text { poderá não compreender. }\end{array}$ & & & \\
\hline 4.4 & $\begin{array}{l}\text { Apresenta as respostas das atividades sugeridas nos } \\
\text { capítulos e orienta o estudante sobre os caminhos que } \\
\text { levam à resolução das questões, justificando a respos- } \\
\text { ta correta, mostrando possíveis respostas equivocadas } \\
\text { que o estudante possa ter feito. }\end{array}$ & & & \\
\hline \multicolumn{5}{|c|}{ Justificativas com exemplificação das respostas parciais e negativas: } \\
\hline
\end{tabular}

\section{BLOCO 5- PROJETO EDITORIAL}

Conforme o PNLD-2012 de Física, o projeto editorial é uma adequação da estrutura editorial e do projeto gráfico, aos objetivos didático-pedagógicos do material didático impresso. 
Quadro 5 - Ficha de avaliação para o Bloco projeto editorial.

\begin{tabular}{|c|c|c|c|c|}
\hline $\mathrm{N}^{\mathrm{O}}$ & Critério & Sim & Parcial & Não \\
\hline 5.1 & $\begin{array}{l}\text { O MDI apresenta capa, verso, página de rosto, apresen- } \\
\text { tação do programa, apresentação do curso e do autor. }\end{array}$ & & & \\
\hline 5.2 & $\begin{array}{l}\text { O MDI traz o sumário organizado na forma de sequên- } \\
\text { cia de conteúdos e permite a rápida localização das } \\
\text { informações. }\end{array}$ & & & \\
\hline 5.3 & O MDI não possui erros de ortografia e/ou impressão & & & \\
\hline 5.4 & $\begin{array}{l}\text { As ilustrações ou tabelas são fáceis de serem compre- } \\
\text { endias, estão integradas ao texto e estão empregadas } \\
\text { em quantidade suficiente para o aprendizado do aluno. }\end{array}$ & & & \\
\hline 5.5 & $\begin{array}{l}\text { As ilustrações ou tabelas presentes na obra estão a- } \\
\text { companhadas dos respectivos créditos e da clara identi- } \\
\text { ficação da localização das fontes ou acervos de onde } \\
\text { foram reproduzidos (PNLD, 2012- Física). }\end{array}$ & & & \\
\hline 5.6 & $\begin{array}{l}\text { As ilustrações apresentam títulos, fontes e datas, no } \\
\text { caso de gráficos e tabelas e, no caso de mapas e outras } \\
\text { representações gráficas do espaço, apresentam legen- } \\
\text { das, escala, coordenadas e orientação em conformidade } \\
\text { com as convenções cartográficas (PNLD, } 2012 \text { - Físi- } \\
\text { ca). }\end{array}$ & & & \\
\hline 5.7 & $\begin{array}{l}\text { Os ícones sinalizam de forma adequada os destaques a } \\
\text { serem dados no texto e estão indicados na margem } \\
\text { esquerda da página. }\end{array}$ & & & \\
\hline \multicolumn{5}{|c|}{ Justificativas com exemplificação das respostas parciais e negativas: } \\
\hline
\end{tabular}

Quadro 6 - Resumo quantitativo dos blocos.

\begin{tabular}{|c|c|c|c|c|c|c|c|c|c|}
\hline \multicolumn{10}{|c|}{ Resumo Quantitativo dos Blocos } \\
\hline Blocos & Nomes & Critérios & $\begin{array}{l}\text { Total } \\
\text { de } \\
\text { crité- } \\
\text { rios }\end{array}$ & $\begin{array}{c}\text { Total } \\
\text { Sim } \\
(\mathrm{S})\end{array}$ & \begin{tabular}{|l|} 
Total: \\
Parci- \\
al (P)
\end{tabular} & $\begin{array}{r}\text { Total: } \\
0,5 \\
\mathrm{P}^{*}\end{array}$ & $\begin{array}{l}\text { Total: } \\
\text { Não } \\
(\mathrm{N})\end{array}$ & $\begin{array}{l}* * \text { Faixa de } \\
\text { Classifica- } \\
\text { ção (Total } \\
\text { de Sim + }\end{array}$ & $\begin{array}{c}\text { Classifi- } \\
\text { cação dos } \\
\text { blocos }\end{array}$ \\
\hline
\end{tabular}




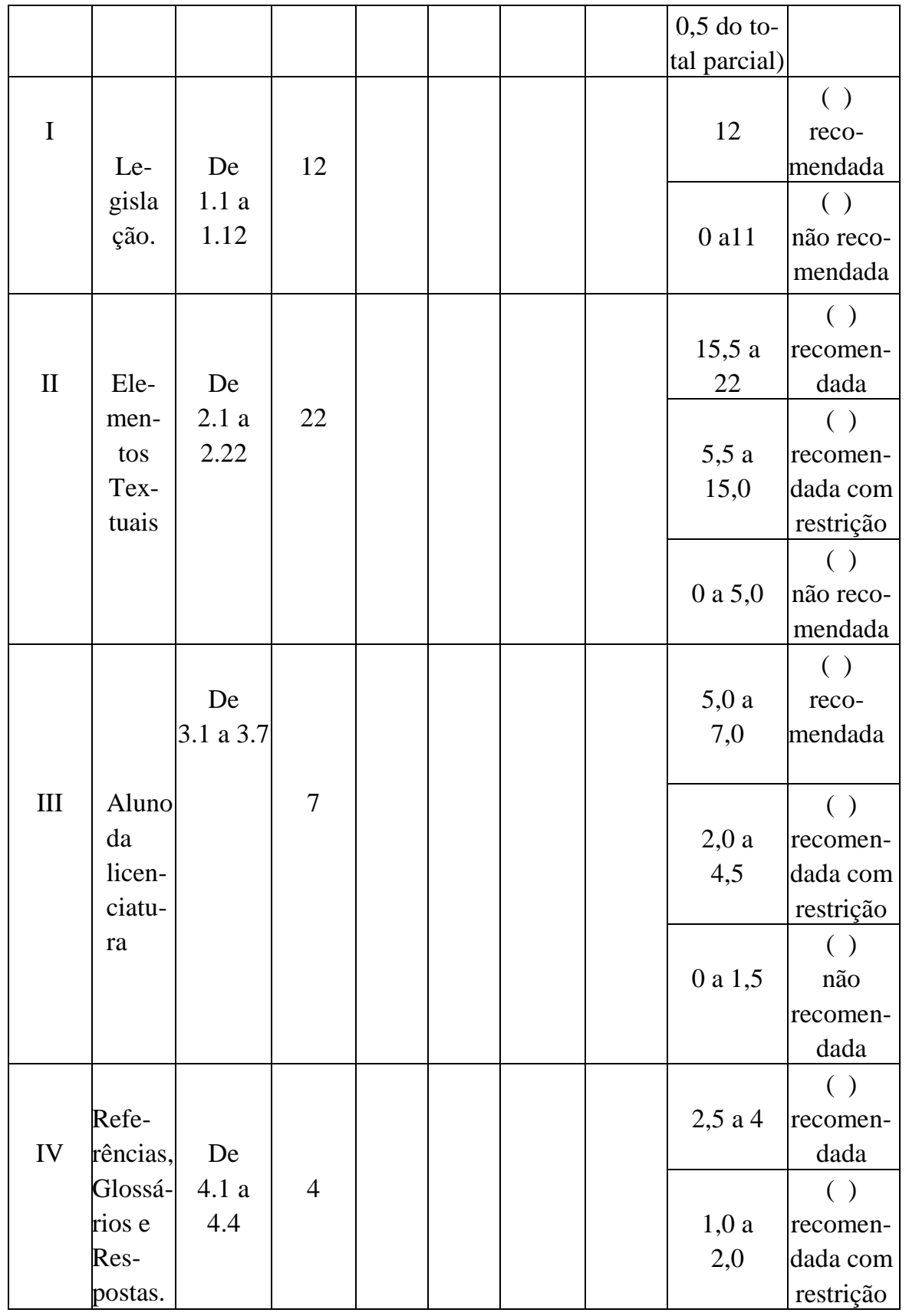




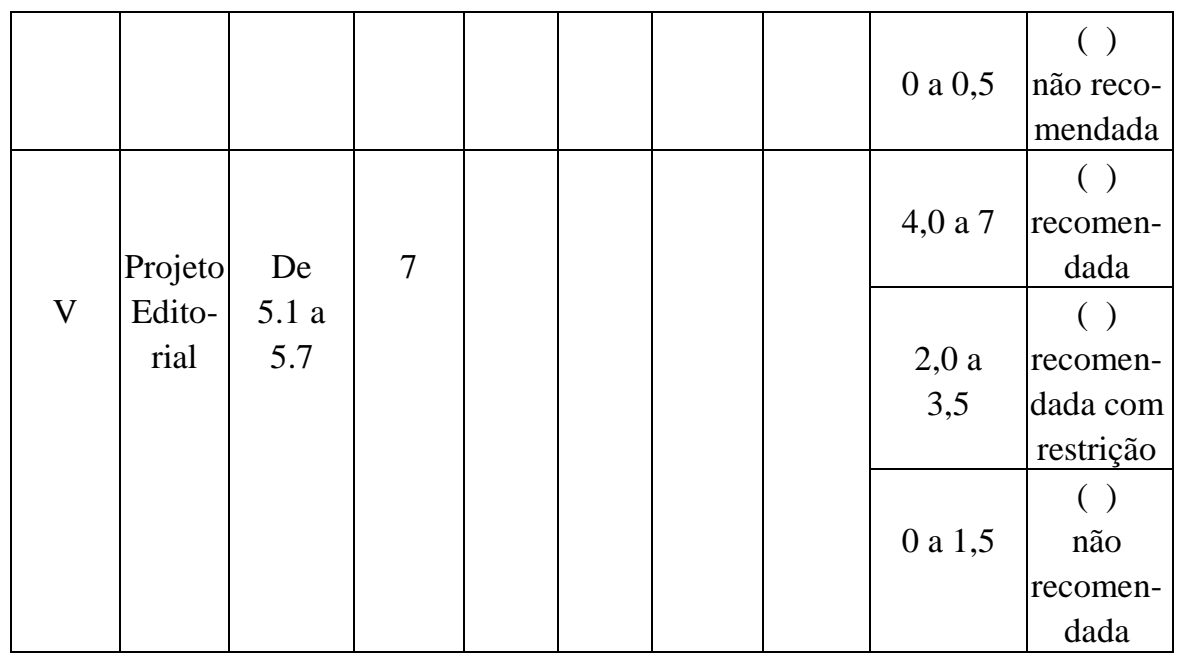

" Conforme sugestão do PNLD-EJA, os itens que atenderam parcialmente os critérios de avaliação do MDI, possui peso 0,5.

**A proporção utilizada na faixa de classificação foi baseada no PNLD-EJA (2011).

Quadro 7 - Resumo quantitativo da obra.

\begin{tabular}{|c|c|c|c|c|c|c|c|}
\hline \multicolumn{8}{|c|}{ Resumo Quantitativo da Obra } \\
\hline Blocos & Nomes & Critérios & $\begin{array}{l}\text { Total de } \\
\text { critérios }\end{array}$ & \begin{tabular}{|c|} 
Total: \\
Sim \\
$(\mathrm{S})$
\end{tabular} & \begin{tabular}{|c} 
Total: \\
Parcial \\
$(\mathrm{P})$
\end{tabular} & $\begin{array}{l}\text { Total: } \\
\text { Não } \\
\text { (N) }\end{array}$ & $\begin{array}{l}\text { Classificação } \\
\text { dos blocos }\end{array}$ \\
\hline I & $\begin{array}{l}\text { Legisla- } \\
\text { ção }\end{array}$ & $\begin{array}{c}\text { De } 1.1 \mathrm{a} \\
1.12\end{array}$ & 12 & & ----- & & $\begin{array}{l}\text { ( ) Recomen- } \\
\text { dada } \\
\text { ( ) Não reco- } \\
\text { mendada }\end{array}$ \\
\hline II & $\begin{array}{c}\text { Elemen- } \\
\text { tos Tex- } \\
\text { tuais }\end{array}$ & $\begin{array}{c}\operatorname{De} 2.1 \mathrm{a} \\
2.22\end{array}$ & 22 & & & & $\begin{array}{l}\text { ( ) Recomen- } \\
\text { dada } \\
\text { ( ) Recomen- } \\
\text { dada com } \\
\text { restrição } \\
\text { ( ) Não } \\
\text { recomendada }\end{array}$ \\
\hline
\end{tabular}

Caderno Brasileiro de Ensino de Física, v. 31, n. 2, p. 429-462, ago. 2014. 


\begin{tabular}{|c|c|c|c|c|}
\hline III & $\begin{array}{c}\text { Aluno da } \\
\text { licencia- } \\
\text { tura }\end{array}$ & $\begin{array}{c}\text { De } 3.1 \mathrm{a} \\
3.7\end{array}$ & 7 & \\
\hline IV & $\begin{array}{l}\text { Referên- } \\
\text { cias, } \\
\text { Glossá- } \\
\text { rios e } \\
\text { Respos- } \\
\text { tas. }\end{array}$ & $\begin{array}{c}\operatorname{De} 4.1 \mathrm{a} \\
4.4\end{array}$ & 4 & $\begin{array}{l}\text { ( ) Recomen- } \\
\text { dada } \\
\text { ( ) Recomen- } \\
\text { dada com } \\
\text { restrição } \\
\text { ( ) Não reco- } \\
\text { mendada }\end{array}$ \\
\hline IV & $\begin{array}{l}\text { Projeto } \\
\text { Editorial }\end{array}$ & $\begin{array}{c}\text { De } 5.1 \text { a } \\
5.7\end{array}$ & 7 & $\begin{array}{l}\text { ( ) Recomen- } \\
\text { dada } \\
\text { ( ) Recomen- } \\
\text { dada com } \\
\text { restrição } \\
\text { ( ) Não reco- } \\
\text { mendada }\end{array}$ \\
\hline $\begin{array}{l}\text { *Resultado } \\
\text { Quantitativo } \\
\text { da avaliação } \\
\text { da obra }\end{array}$ & \multicolumn{4}{|c|}{$\begin{array}{l}\text { RECOMENDADA (5 blocos recomendado). } \\
\text { RECOMENDADA COM RESTRIÇÃO (toda combinação que } \\
\text { contenha uma recomendação com restrição e não tenha uma classi- } \\
\text { ficação não recomendado). } \\
\text { NÃO RECOMENDADA (quando um dos blocos tiver a classifica- } \\
\text { ção não recomendado). }\end{array}$} \\
\hline
\end{tabular}

* Adaptado de PNLD/EJA (2011).

\section{Considerações finais}

Esse trabalho apresenta uma proposta de critérios para a avaliação de materiais didáticos impressos de história da ciência para a educação a distância com o objetivo de melhorar a qualidade os materiais oferecidos. Sabe-se que existe uma evolução do número de matrículas dos alunos na Educação a Distância (EAD), o que sinaliza para uma demanda maior de produção de objetos de aprendizagem, em especial os materiais didáticos impressos. Essa expansão acarreta uma preocupação com a qualidade dos conteúdos presentes nesses materiais.

Os critérios construídos nesse artigo são fundamentados nos documentos oficiais do Ministério da Educação (Legislação em EAD, LDB, Diretrizes curriculares para a formação de professores, $\mathrm{PCN}, \mathrm{PCN}^{+}$e $\mathrm{PNLD}$ ), nos modelos de a- 
prendizagem descritos por Porlán e Rivero (1998), e em dois livros destinados à Educação a distância, em três materiais didáticos impressos de história da ciência para a EAD e numa revisão de literatura sobre o ensino de história da ciência. Os critérios são reunidos em cinco blocos e distribuídos numa ficha de avaliação da obra.

Os critérios descritos nos blocos são complementares e foram construídos tendo como eixo condutor o aluno da licenciatura em física a distância. Assim, o material didático impresso de história da ciência deve priorizar além dos conteúdos de história da ciência, uma forma de transposição didática desses conteúdos. Entende-se que o estudo de caso histórico seja uma estratégia viável para se escrever um MDI, por permitir mensurar a evolução do conhecimento do aluno.

Outro aspecto que merece destaque é a posição da disciplina história da ciência na matriz curricular dos projetos políticos pedagógicos dos cursos de licenciatura em física a distância. Na UFSC, UFRJ ${ }^{8}$ e UFES, a história da ciência aparece apenas no penúltimo ou no último período do curso. Isto produz no aluno uma visão equivocada da construção do conhecimento científico, pois ele aprende primeiro o resultado de uma teoria científica (através, por exemplo, dos conteúdos das disciplinas básicas da Física: mecânica, termodinâmica, eletromagnetismo) e, só depois conhece como esses conteúdos foram construídos. Assim, o aluno adquire inicialmente uma visão, segundo Gil-Pérez et al (2001), uma visão aproblemática, ahistórica, dogmática e fechada da ciência ${ }^{9}$. Para evitar essa distorção, talvez a melhor maneira seja iniciar a disciplina de História da Ciência a partir do primeiro período do curso.

Outro ponto que podemos considerar é a baixa carga horária semanal $\left(\mathrm{CHS}^{10}\right)$, destinada à HC nas matrizes curriculares da UFES ${ }^{11}(45 \mathrm{~h})$ e da UFRJ

\footnotetext{
${ }^{8}$ O curso de licenciatura em física a distância da UFRJ é vinculado à Fundação Centro de Ciências e Educação Superior a Distância do Estado do Rio de Janeiro (CECIERJ).

A visão aproblemática, ahistórica, dogmática e fechada da ciência é caracterizada pela transmissão de conhecimentos já elaborados aos alunos, sem que esses possam perceber ou identificar as dificuldades encontradas, as possibilidades e limitações do conhecimento científico.

${ }^{10}$

CHS- carga horária semanal. Na educação a distância a CHS representa o tempo mínimo de estudo dedicado a cada disciplina por semana.

11

Disponível em: <http://www2.neaad.ufes.br/arq_uteis/grade_curricular_fisica.pdf >. Acesso em: 09 mar. 2014.
}

Caderno Brasileiro de Ensino de Física, v. 31, n. 2, p. 429-462, ago. 2014. 
(60 h). A carga horária de história da ciência dessas instituições oferecem valores inferiores, por exemplo, à carga horária destinada as disciplina de Física II dessas universidades. Essa disciplina aparece dividida em Física II-A e Física II-B e, possuem carga horária total de $120 \mathrm{~h}$, sendo 80 horas de teoria e 40 horas de atividades práticas de laboratório. A carga horária de história da ciência da UFSC ${ }^{13}$ é de 80h, valor idêntico, por exemplo, às $80 \mathrm{~h}$ destinadas ao ensino da Física Básica CII.

Embora entendamos que somente a elevada carga horária de uma disciplina, não seja indicador de qualidade de ensino, oitenta horas semanais destinadas ao estudo da história da ciência através do MDI ou do ambiente virtual, permite ao aluno da licenciatura em física a distância EAD, um conhecimento mínimo de conteúdos teóricos e práticos dessa disciplina. $\mathrm{O}$ conhecimento prático de história da ciência é obtido através da explicação de estratégias de ensino vinculada ao aprendizado de conteúdos. Essas estratégias envolvem o uso de experimentos históricos e teatros (que podem ser realizados no polo de apoio presencial), a elaboração e aplicação de estudos de caso histórico, entre outros.

Acreditamos que os critérios apresentados nesse artigo induzem a produção de MDI de história da ciência potencialmente significativos (AUSUBEL, 2003), pois buscam estabelecer uma conexão entre a teoria e a práxis do aluno de licenciatura em física a distância.

O contato com esses critérios de avaliação pode acontecer ainda na graduação. Os alunos do Programa de Iniciação à Docência (PIBID) ou de iniciação científica (PIBIC), de posse desse instrumento podem analisar os MDI de história da ciência para a EAD, propondo melhorias nesses materiais, ou até mesmo propondo outros critérios para atender as outras disciplinas ofertadas na modalidade a distância, e/ou presencial.

A escolha dos MDI, no entanto, transcende a observação dos aspectos gráficos, conteúdos, linguagem ou atividades propostas. Segundo Vasconcelos e Souto (2003), a participação do professor na escolha dos recursos didáticos, especialmente o material didático impresso, deve estimular a definição de critérios que

${ }^{12}$ Disponível em: <http://cederj.edu.br/cederj/?page_id=219>. Acesso em: 09 mar. 2014.

${ }^{13}$ Disponível em: <https://ead.ufsc.br/fisica/grade-curricular-uab-2-2013/>. Acesso em: 09 mar. 2014. 
instrumentalizem o processo de escolha e fomentem a discussão sobre os caminhos da educação.

Talvez, os critérios descritos nesse artigo sejam o embrião para a construção de critérios para avaliar MDI de outras disciplinas da EAD. O conjunto desses instrumentos de avaliação poderia ser inserido em um desejável PNLD para os cursos superiores a distância, com o objetivo de melhorar a qualidade desses materiais.

\section{Referências bibliográficas}

ABED. Associação Brasileira de Educação a Distância. Censo Ead BR. Disponível em: 〈http://www.abed.org.br/censoead/CensoEaD2012.pdf〉. Acesso em: 15 abr. 2012.

ABED. Associação Brasileira de Educação a Distância. Censo Ead BR. Disponível em: 〈http://www.abed.org.br/censoead/CensoEaD2011.pdf〉. Acesso em: 15 abr. 2012.

AUSUBEL, D. P. Aquisição e retenção de conhecimentos: uma perspectiva cognitiva. Tradução: Lígia Teopisto. 1. ed. Lisboa: Paralelo Editora, jan. 2003. 226 p.

BEAHR, P. A. Modelos pedagógicos em educação a distância. Porto Alegre: Artmed, 2009.

BIZZO, N. Intervenções alternativas no ensino de Ciências no Brasil. In: ENCONTRO PERSPECTIVAS DO ENSINO DE BIOLOGIA, 6, 1997, São Paulo. Anais...

BORGES, R. M. R. Em debate: Cientificidade e Educação em Ciências. Porto Alegre: SE/CECIRS, 1996.

BRASIL. Conselho Nacional de Educação. Câmara de Educação superior. Resolução ${ }^{0}$ 9, de 11 de março de 2002. Disponível em:

<http://portal.mec.gov.br/cne/arquivos/pdf/CES09-2002.pdf〉. Acesso em: 27 fev. 2014.

BRASIL. Conselho Nacional de Educação/Conselho Pleno. Resolução CNE/CP 2, de 19 de fevereiro de 2002. Disponível em: 
<http://portal.mec.gov.br/cne/arquivos/pdf/CP022002.pdf〉. Acesso em: 27 fev. 2014.

BRASIL. Decreto 5.622, de 19 de dezembro de 2005. Regulamenta o art.80 da lei $\mathrm{n}^{\circ}$ 9394, de 20 de dezembro de 1996, que estabelece as diretrizes e bases da educação nacional. Disponível em:

$\langle$ http://portal.mec.gov.br/seed/arquivos/pdf/dec_5622.pdf〉. Acesso em: 07 jan. 2013.

BRASIL. Diretrizes Curriculares Nacionais para a Formação de Professores da Educação Básica (DCNFPEB). Disponível em:

<http://portal.mec.gov.br/seesp/arquivos/pdf/res1_2.pdf〉. Acesso em: 04 set.2013.

BRASIL. Diretrizes Curriculares Nacionais Para o Ensino Médio (DCNEM). Disponível em: <http://portal.mec.gov.br/seb/arquivos/pdf/res0398.pdf〉. Acesso em: 29 ago. 2013.

BRASIL. Fundo Nacional de Desenvolvimento da Educação. Resolução/CD/FNDE $\mathbf{n}^{0}$ 38, de 15 de outubro de 2003. Disponível em: $<$ http://www.fnde.gov.br/fnde/legislacao/resolucoes/item/4256resolu\%C3\% A7\%C3\%A3o-cd-fnde-n\%C2\%BA-38,-de-15-de-outubro-de-2003>. Acesso em: 27 fev. 2014.

BRASIL. Fundo Nacional de Desenvolvimento da Educação. Resolução/CD/FNDE $\mathbf{n}^{0} \mathbf{1 8}$, de $\mathbf{2 4}$ de abril de 2007. Disponível em: <http://www.fnde.gov.br/fnde/legislacao/resolucoes/item/3139resolu\%C3\%A7\%C3\%A3o-cd-fnde-n\%C2\%BA-18-de-24-de-abril-de-2007>. Acesso em: 27 fev. 2014.

BRASIL. Guia do Programa Nacional do Livro Didático (PNLD-2011 EJA). Disponível em: <http://www.fnde.gov.br/programas/livro-didatico/guia-dolivro/item/512-guia-pnld-2011-educa\%C3\%A7\%C3\%A3o-de-jovens-e-adultos $>$. Acesso em: 02 ago. 2013.

BRASIL. Guia do Programa Nacional do Livro Didático (PNLD-2012-Física). Disponível em: <http://www.fnde.gov.br/programas/livro-didatico/guia-dolivro/item/2988-guia-pnld-2012-ensino-m\%C3\%A9dio>. Acesso em: 02 ago. 2013. 
BRASIL. Lei de Diretrizes e Bases da Educação Nacional (LDB). Disponível em: 〈http://portal.mec.gov.br/arquivos/pdf/ldb.pdf〉. Acesso em: 28 ago. 2013.

BRASIL. Ministério da educação. Instituições de Educação Superior e Cursos Cadastrados. Consulta avançada. Disponível em: 〈http://emec.mec.gov.br〉. Acesso em: 01 mar.2014.

BRASIL. Orientações Educacionais Complementares aos Parâmetros Curriculares Nacionais $\left(\mathbf{P C N}^{+}\right)$. Disponível em:

〈http://portal.mec.gov.br/seb/arquivos/pdf/CienciasNatureza.pdf〉. Acesso em: 05 set. 2013.

BRASIL. Parâmetros Curriculares para o Ensino Médio (PCN) - Parte I Bases Legais. Disponível em:

〈http://portal.mec.gov.br/seb/arquivos/pdf/blegais.pdf〉. Acesso em: 02. set. 2013.

BRASIL. Parâmetros Curriculares para o Ensino Médio (PCN) - Parte IIICiências da Natureza, Matemática e suas Tecnologias. Disponível em: <http://portal.mec.gov.br/seb/arquivos/pdf/ciencian.pdf〉. Acesso em: 02 set. 2013.

BRASIL. Parecer CNE/CP 9/2001 (homologado). Despacho do Ministro em 17 de Janeiro de 2002. Diretrizes Curriculares Nacionais para a Formação de Professores da Educação Básica, em nível superior, curso de licenciatura, de graduação plena. Diário Oficial da União, Seção 1, p. 31 de 18 Janeiro de 2002.

CAMARGO, O. O que é cidadania. Disponível em:

<http://www.brasilescola.com/sociologia/cidadania-ou-estadania.htm>. Acesso em: 24 set. 2013.

CARVAlHO, J. M. de. Cidadania no Brasil: o longo caminho. Rio de janeiro: Civilização Brasileira, 2002.

CORDEIRO, M. D.; PEDUZZI, L. O. Q. As Conferências Nobel de Marie e Pierre Curie: a gênese da radioatividade no Ensino. Caderno Brasileiro de Ensino de Física, v. 27, n. 3, p. 473-514, 2010.

DIAS, P. M. C.; SAPUNARU, R. A. História da Física I. Formação das categorias do pensamento em física (século VI a.C. - século XVII d.C.). Universidade Federal do Rio de Janeiro, Pontifícia Universidade Católica do Rio de Janeiro, 2013. 
DIAS, P. M. C.; SAPUNARU, R. A. História da Física II. Estrutura Mecanicista da Natureza. Universidade Federal do Rio de Janeiro, Pontifícia Universidade Católica do Rio de Janeiro, 2013.

EL-HANI, C. Notas sobre o ensino de história e filosofia da ciência na educação científica de nível superior. In: SILVA, C. C. (Org.). Estudos de História e Filosofia das Ciências: subsídios para Aplicação no Ensino. São Paulo: Livraria da Física, 2006.

FERREIRA, C. MEIRELLES, R. O Ensino de Ciências nas Diretrizes Curriculares Nacionais para a Formação de Professores da Educação Básica no Brasil: um estudo preliminar. Disponível em:

<http://www.nutes.ufrj.br/abrapec/viiienpec/resumos/R0932-1.pdf〉. Acesso em: 20 abr. 2013.

FORATO, T. C. M.; PIETROCOLA, M.; MARTINS, R. A. Historiografia e natureza da ciência na sala de aula. Caderno Brasileiro de Ensino de Física, v. 28, n. 1, p. 27-59, abr. 2011.

Gil-PÉREZ, D.; MONTORO, I, A.; CACHAPUZ, A; PRAIA, J. Para uma imagem não deformada do trabalho científico. Ciência e Educação, v. 7, n. 2, p. 125-153, 2001.

GOUVÊA, G.; OLIVEIRA, C. I. Educação a Distância na formação de professores: viabilidades, potencialidades e limites. 4. ed. Rio de Janeiro: Vieira e Lent, 2006.

GUERRA, A; REIS, J. C.; BRAGA, M. Tempo, espaço e simultaneidade: uma questão para os cientistas, artistas, engenheiros e matemáticos no Século XIX. Caderno Brasileiro de Ensino de Física, v. 27, n. 3, p. 568-583, 2010.

HODSON, D. Teaching and learning science. Buckingham: Open University Press, 1998.

MANTOVANI. K. P. O Programa Nacional do Livro Didático - PNLD: Impactos na qualidade do ensino público. 2009. Dissertação (Mestrado) - Faculdade de Filosofia, Letras e Ciências Humanas, Universidade Estadual de São Paulo. 
MATTEWS, M. R. História, Filosofia e Ensino de Ciências: a tendência atual de reaproximação. Caderno Catarinense de Ensino de Física, v. 12, n. 3, p. $164-$ 214, dez. 1995.

MEDINA, M.; BRAGA, M. O teatro como ferramenta de aprendizagem da física e de problematizarão da natureza da ciência. Caderno Brasileiro de Ensino de Física, v. 27, n. 2, p. 313-333, ago. 2010.

MORAN, J. M. O que é educação a distância. Disponível em:

<http://www.eca.usp.br/moran/dist.htm>. Acesso em: 10 jan. 2013.

NOSELLA, M. de L. C. D. As belas mentiras. A ideologia subjacente dos textos didáticos. São Paulo: Moraes, 1981.

PEDUZZI, L. O. Q. Evolução dos Conceitos da Física. Florianopolis: UFSC/EAD/CED/CFM, 2011.

PORTO, F. S. et al. Exposições museológicas para aprendizagem de física em espaços formais de educação: um estudo de caso. Caderno Brasileiro de Ensino de Física, v. 27, n. 1, p. 26-62, 2010.

PORLÁN, R.; RIVERO, A. El conocimento de los profesores. Servilha: Díada, 1998.

PRETI, O. Produção de Material Didático Impresso: Orientações Técnicas e Pedagógicas. Cuiabá: UAB/UFMT, 2010.

REIS, E. M.; LINHARES, M. P. Ambientes virtuais de aprendizagem no Ensino de ciências no Proeja. In: SIMPÓSIO NACIONAL DE ENSINO DE FÍSICA, XIX, 2011, Manaus. Atas...

RESNICK, R.; HALLIDAY, D.; KRANE, K. Física. 4. ed. Rio de Janeiro: LTC, 2007. v. 1, 2, 3, 4 .

RINALDI, E.; GUERRA, A. História da ciência e o uso da instrumentação: construção de um transmissor de voz como estratégia de ensino. Caderno Brasileiro de Ensino de Física, v. 28, n. 3, p. 653-675, 2011.

RODRIGUES, C. Configurações das abordagens pedagógicas da educação a distância. Revista Brasileira de Aprendizagem Aberta e a Distância, v. 10, 2011. 
SCHRÖDINGER, E. A Natureza e os gregos seguido de ciência e humanismo. Lisboa: Edições 70, 2003.

SHULMAN, L. S. Those who understand: Knowledge growth in teaching. Educational Research, Oxfordshire, v. 15, n. 2, p. 4-14, 1986.

STINNER, A.; MCMILLAN, B.; DON METZ; JILEK, J.; KLASSEN, S. The Renewal of Case Studies in Science Education. Science \& Education, v. 12, p. 617-643, 2003.

TARDIF, M. Saberes docentes e formação profissional. Petrópolis: Vozes, 2002.

TORÍBIO, A. M. V. História da Física. Universidade Federal do Espírito Santo Núcleo de Educação Aberta e a Distância, Vitória, 2012.

VASCONSELOS, S. D.; SOUTO, E. O livro didático de Ciências no Ensino Fundamental- Proposta de Critérios para a análise de conteúdo zoológico. Ciência $\&$ Educação, v. 9, n.1, p. 93-104, 2003. 